\title{
Where My Cord is Buried: WoDaaBe Use and Conceptualization of Land
}

\author{
Kristín Loftsdóttir ${ }^{1}$
}

\section{Introduction}

"Now they have started thinking about it [land rights], but it is probably just a little too late. I feel sorry for them" (Government official on WoDaaBe and land entitlement).

A general conception among many government officials and those working in relation to development seems to be that WoDaaBe simply do not have attachment to land, and traditionally have had no conception of land as a home. These issues are increasingly important in present day Niger, where claims of land have become a very central issue. The goal of this paper is to discuss resource use by a specific lineage group of WoDaaBe and their conceptualization of land. I will explain the dynamics of the seasonal movements of WoDaaBe, which I believe are partly the reason that WoDaaBe are often seen as not having an attachment to land. I will also discuss concepts tied to the WoDaaBe conceptualization of land. I place my discussion in a broad political and ecological context, explaining the WoDaaBe situation within the nation state. Studies on environmental issues have increasingly emphasized power and politics as embodied within ecological realities and meanings (J. Greenberg and T. Park 1994; Little 1999), while studies of pastoral societies have similarly shown that pastoral systems are not merely adaptive systems but must be contextualized within a larger context of national and transnational politics (see review E. Fratkin 1997). Scholars have from such perspectives demonstrated the importance of various forms of risk management among Sahelian societies to respond to various political-social and ecological variables (T. Park 1993; also D. Rain 1999). Mobility, being one form of risk management, constitutes for the WoDaaBe an adaptive mechanism to the interwoven social and ecological circumstances, forming the key to understanding their land use, as being simultaneously entangled with their ethnic identity, their sense of place, as well as social memory and meaning.

The discussion is divided into three parts. The first part focuses on the political and social organization of the WoDaaBe, the relationship between lineages as well as the WoDaaBe household. The goal is to provide basic information about WoDaaBe social structure that is necessary to an understanding of their use of resources. Exploitation of a resource base is the topic of the second part, focusing on the challenges of different seasons, the exploitation of water, and migrational movements. The third part looks at WoDaaBe conceptualization of land and the history of resource use of a particular lineage group, placing the general discussion in the context of current politics of land entitlement

1. Kristin Loftsdottír is an Assistant Professor at the University of Iceland. 
in Niger, emphasizing how WoDaaBe see themselves as having been marginalized in this process.

WoDaaBe society is based upon a segmentary lineage system, which ideally divides into smaller and smaller segments, in E.E. Evans-Pritchard's classical sense (EvansPritchard 1940). The different segments are often geographically separated, occupying different ecological zones, as well as being exposed to somewhat different political environments. This paper focuses on a segment of the Godjanko'en, who live in the area of Tchin Tabaraden. A great variation exists within WoDaaBe society, and thus all broad generalizations about them should be taken with care. The information presented here should be seen as referring to a specific group of WoDaaBe, whose circumstances do not necessarily apply to all WoDaaBe. As anthropologists have emphasized in their approach, discussion of specific segments of society can be important in order to give a detailed and a holistic view of the use and conceptualization of land.

The information for this paper was gathered in the context of my dissertation research, conducted from August 1996 through June 1998 (K. Loftsdóttir 2000). The research was made possible with a Travel grant from the Nordic Africa Institute, and an Ambassadorial Scholar scholarship from the Rotary International. I am grateful to these institutions for having faith in my project. My WoDaaBe research assistants, helped me extensively in formulating the second part of the paper. This issue was especially important for those who had gone with me to conduct many of the interviews taken with non-WoDaaBe, repeatedly hearing people say that WoDaaBe had no attachment to land. Thus, even though the paper is the result of formal and informal discussions with various WoDaaBe, many of the direct quotes come from interviews and discussions with my research assistants regarding these issues.

\section{The Social Structure}

\subsection{Pastoral societies}

Much has been discussed in relation to the concept of pastoral or nomadic people, and various definitions have been put forward regarding what constitutes pastoral people or pastoral nomads, usually presented as opposed to agriculturalists. I want to make a brief addition to this discussion, even at the risk of repeating what has already been said, the reason being that an understanding of these concepts is crucial to the subject under discussion. The concept of nomads has been used by some to characterize all mobile groups, including hunters and gatherers, whereas others have associated the concept nomad with animal husbandry (A.Khazanov 1994:15). The most common way of classifying pastoral nomads is by identifying how much they are involved in agricultural activities, even though the terms of classification used are not always the same (see for example: A.Khazanov 1994:17-25). The problem with such a classification is that the boundaries between agriculture and pastoralism are fluid and changing. A single group can pass from one category to another as a response to environmental fluctuations or a changing social-political environment.

Johnson, in discussing this problem, maintains that pastoral nomads should be seen on a continuum between a purely sedentary society and a hypothetical form (nonexistent) of pure nomadism, which has no need for agricultural products (D.Johnson 1969:12). From this perspective, pastoral nomadism can be defined as an "adjustment to a particular set of ecological conditions, at a given technological level, along a continuum of numerous 
potential economic possibilities" (D.Johnson 1969:17; see also A.Maliki 1988; J.Swift 1979:1-2). In addition, pastoralism can also be seen as implying that animal husbandry is dominant both in an economic and cultural sense, in the way that the animals serve as a source of images and metaphors for the culture. In this sense, pastoralism is not only an occupation, but a way of life (J.Galaty and D.Johnson 1990:2,5) that creates a meaningful existence.

A BoDaaDo (the singular of WoDaaBe) explained once to me that: "nganayko hokki na'i gonga, o hokki na'i sembe ma'ako fuu," which can be translated as "a herder gives his herd the truth [i.e., he takes his work seriously], he gives it all his strength." This definition stresses the holistic view of pastoralism, similar to the recent scholarly discussions explained above. Thus for nomadic pastoralism, other occupations practiced sometimes are means of returning to the pastoral economy. The quotation above is important because it identifies someone as being a herder because herding is a way of life for that person.

\subsection{Political Organization of the WoDaaBe}

WoDaaBe are divided into two basic lineages, that have a mythic origin in two brothers Ali and Degi. The two lineages carry their names, being referred to as Alidjam and Degireul. Various origin myths exist, however, in WoDaaBe society that do not refer to the brothers but reflect more on how WoDaaBe as a single group came into being in a mythic past (see M.Dupire 1962:29-37)

Each of these two lineages divides into increasingly smaller segments. Taking a group from the research area as an example, the Utei Balebe are a segment of the Utei, which is a segment of the Godjanko'en, which again is a segment of the Degereul. The model below can be seen as an attempt to show this division even though it in no way depicts the diversity within the lineages in general.

Figure 1. Model of segment division

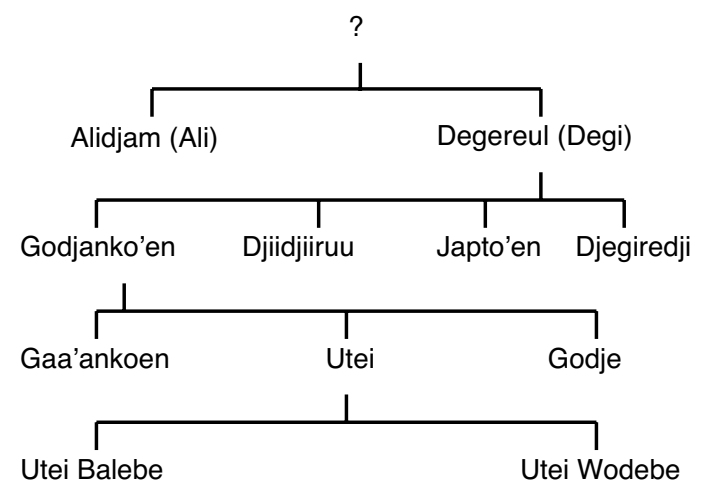

The segments are headed by an ardo, who traditionally probably constitutes the highest authority within WoDaaBe society. The ardo is a link to the government, assisting with tax collection, and also has authority to rule in disputes within the lineage group. In addition, the ardo is influential in decision making regarding migrations and seasonal movements. The ardo is traditionally an inherited position, going from the father to the 
oldest son, even though there are some exceptions to this. The group can affect, to a certain extent, who takes over the position, because the authority of the ardo is simply based on peoples willingness to "follow," thus to accept the person's authority. This means that an individual can break away from the authority of a particular ardo and follow another, or a group could refuse to accept the authority of a specific ardo.

Another authority in WoDaaBe society is the lamido (pl. lamibe). Historical references state that probably during the time of the Sokoto empire, the first WoDaaBe person gain the position of lamido. The WoDaaBe group in the area of research lost this position of authority, and were in colonial times placed under the authority of at least several lamibe from the ethnic group Fulani. Oral accounts depict these Fulani lamibe very negatively, older people claiming that they had to pay heavy taxes, and that disputable justice was exercised. In 1973, the WoDaaBe of Tahoua acquired their own lamido, which is presently their highest political authority.

It can be pointed out that the WoDaaBe society is not caste based as has been observed in relation to some other Fulani societies, but is a relatively egalitarian society (For a discussion of more stratified Fulani society in relation to land see for example (T.Ngaido 1993).

\subsection{Relations between different lineages}

Even though WoDaaBe conceptualize themselves as one group deriving from a common ancestry, a lot of differentiation exists within the WoDaaBe lineages. Some lineages within WoDaaBe social organization express a great deal of hostility toward each other, whereas relations between other lineages are more relaxed. Conflicts between members of different lineages are not uncommon, some even resulting in deaths. I know one example where conflict between two lineages had escalated to the point that one lineage group saw itself as forced to migrate to a different area. As Dupire (1962) points out most members of the lineages see a large number of differences within the WoDaaBe themselves. Dupire writes, "Every lineage possesses, in its own view, a distinctive welldefined character" (M.Dupire 1962:284, author's translation). It can be added that the WoDaaBe also have a strong view of the characteristics of members of lineages other than their own, very often negative ones (for example; The Godjanko'en claim that the Bikaroni'en are cowards and that the Djiigiiru never finish what they eat)

Ethnographic work demonstrates some difference in organization and life-style between different groups of WoDaaBe. There is some variation in the extent of involvement in other commercial activities, in the making of saga (a table), or of what is considered appropriate behavior, to mention a few examples. Lineages have also to some extent slight vernacular differences, expressed in pronunciation and choice of concepts. As far as I know, no systematic research has been done on this matter, so it is difficult to state how much difference there is. ${ }^{2}$ Loan words obviously differ between different areas of WoDaaBe groups, because they are in contact with diverse ethnic groups. Among the group I stayed with for example, the concept ardo was almost never used (even though well known), but the similar Hausa concept Hakkimidjo was frequently used.

2. Comparison has been done by E. Mohammadou, (1970) on the difference of concepts used by the Fulani (Jallinko'en), and some Alidjam WoDaaBe groups. 


\subsection{The appropriation of animals}

The WoDaaBe manifest their ownership of their animals by cutting their ears, an act which is described as "djelgul" (M.Dupire 1962 writes "jelgol”) "e mi yiidi mi djela na'i am." This is done at a specific time of the year, in a month which carries the name Jele'tenduu'du, a name deriving from the word djelgul. The whole month from the day in which the marking is done is seen as desirable to establish social relationships, for example for activities related to marriage.

Not all animals are marked in this way, only cows, sheep, goats and donkeys. Thus dogs, horses and camels are without such a mark. I suggested to a BoDaaDo informant that this could reflect a difference between animals that have traditionally been owned by WoDaaBe (i.e. those that are marked) and those that were recently integrated into their economy. My friend did not find this explanation convincing, and suggested instead that this is more likely to do with the animals marked being owned in greater numbers, than the ones that are not marked.

My WoDaaBe consultants told me that this marking is done to show WoDaaBe ownership of the animal, distinguishing it from the ownership of other ethnic groups, thus heavily emphasizing the practical aspect of the marking. This also interestingly assumes that WoDaaBe would not conflict among themselves about ownership of animals. Dupire in her writing, on the other hand, emphasizes the marking of the animals as an important manifestation of WoDaaBe identity. According to Dupire, the mark of ownership of the animals becomes a symbol of a common ancestry. The logic is circular: "the same ancestry hence the same sign, the same sign hence the same ancestry" (M.Dupire 1962:286). At the time she is writing only four types of marks exist for all different lineages of WoDaaBe. It is interesting to note in this context that she reports that the different lineages within the Degiredji group all have the same mark, whereas within the Alidjam three separate marks are to be found.

Discussing this with a BoDaaDo consultant, he wanted to de-emphasize the importance that Dupire places on the djelgul as a unification symbol of the WoDaaBe. He pointed out in this context that djelgul can simply be translated as a "symbol," or "mark" in English, and the concept itself is thus simply referring to marking ones property, and can be used in various other contexts as well that do not have anything to do with livestock or WoDaaBe. My friend thus did not see the djelgul of animals being an important part of the identity of the WoDaaBe. He seemed to think that she misunderstood the concept itself, believing that it applied just to this action, rather than just referring to the general concept of "symbol or mark." The djelgul of the ear is thus not a djelgul of the WoDaaBe, meaning a source of pride, but simply serves to mark certain ownership. The fact that some similarities and differences are observed among how different groups mark their animals is another issue.

He also pointed out that humans have djelgul just as animals. The djelgul of the WoDaaBe being a stick, the braiding of the hair etc., and the djelgul of Hausa being different from the djelgul of the Tuaregs. In my view this is a rather interesting observation; both people and animals are marked to classify them and distinguish them from their neighbors. The key here could be the concept of belonging, the djelgul shows to whom both a certain person and a certain animal belongs. This observation is not completely different from Dupire's, but it suggests the djelgul is a sign of boundaries rather than unification, of borders rather than a source of identification. Thus even though some WoDaaBe today do not conceptualize the djelgul as having other than economic and 
practical significance, it still indicates some kind of similar metaphorical separation of both WoDaaBe animals and WoDaaBe people from other people and animals who belong to other groups.

Looking further at the djelgul as a source of information about boundaries between groups, it can be observed in relation to the group I studied that marks which at first glance seem similar, are not so when closely observed. The Bikaron'en, Japto'en, and Godjanko'en are the only groups about which I have detailed information, but it was pointed out to me that the mark is actually not the same if you look closely. The Bikaron'en make a deeper cut than the Godjanko'en, and the Japto'en take off the top part of the ear (this cut is actually called djebite).

Looking at the marking done by groups other than WoDaaBe we can also see interesting differences that are probably caused by historical development. The Tuaregs, in the area studied, used a completely different method, burning a sign on their animals. According to J.Nicolaisen $(1963 ; 138)$ all northern Tuaregs cut the ear of the sheep and the goats, but brand their camels and donkeys. The same, I have been told, is done by the Hausa, but the Fulani use a similar cut to the WoDaaBe but only cut one ear of the animal, not both ears as the WoDaaBe do.

\subsection{The household}

The WoDaaBe home is extremely well adapted to a nomadic lifestyle. One wuro (pl. gure) is composed of several smaller units called cuudi (sing. suudu) or even by only one. ${ }^{3}$ A half circle of dead branches (licce) marks the suudu, its opening always to the west. The cuudi are lined up from south to north, in a specific hierarchical order depending on the relationship between the people of the wuro. The hierarchy within men ascends from south to north, but that for women ascends from north to south. Thus, if two brothers occupy one wuro, the suudu of the older brother would be to the south of the younger brother. The first wife, however, has her house to the north of the second wife. Men state openly that the house belongs to the woman (debbo djei suudu); if a man has no wife, he has no house. All the objects of the house belong to the woman, and she is responsible for packing them and the house and rebuilding it after each movement. However, it can be pointed out (even though it is not stated by the WoDaaBe themselves) that it is the man who gets the wuro; because men make the wuro together, a woman does not have a choice with whom she makes her house, and where to make it after each movement. A man is the head of the house (jom wuro), ${ }^{4}$ making important decisions concerning it.

In front of each suudu is the dangul (calf rope). The dangul is a part of the house itself, thus making the house of the WoDaaBe an integrated space of human and animal settlement. When I ask children or adults to draw me a picture of their house, they always include the dangul with the licce, saga, and leso (see below). Sometimes cows are included but almost never people. Frequently in the night and in the evening the cows sleep behind the dangul, and thus roam freely within the space that can be defined as a house. The dangul is also a sign of prosperity. To symbolize how difficult some years have been, people say "that year we did not have any calf for our dangul." A man having more

3. The concept "house" in English can be applied to both the Fulfulde concepts wuro, and suudu, even though these two concepts have in no way the same meaning.

4. Women are also sometimes called jom wuro. 
that one wife, splits his dangul, placing part of it in front of each wife's suudu. There she will milk those cows to which she has the right.

Within the suudu are the saga and the leso. The saga (table) is situated in the north, and on it are placed many of the belongings of the house. On each side of the saga stands a carefully constructed eletel. Today the eletel is only a decoration, with two empty fandu (gourds) inside. But at one time it served as container for a mixture of beans called vasavasari, which was kept for a long time, a sign of the richness of the house. In the back of the saga are both the kaggu tummude, which is a rope net containing several calabashes, and the hendere (or lebe'o), ${ }^{5}$ which is a woven container, carrying the woman's clothing. In the front of the saga are the birdude and the jenerde. The birdude is the calabash which is used for milking. It is different from other calabashes because it is never decorated and has a very smooth surface on the inside. Sometimes it has laejake (a talisman) attached to it. If the birdude is kept at the saga it is usually put on the top of the jenerde, but if it is placed on the earth it is placed to the north of the saga. The jenerde can be defined as the calabash where people keep their milk. Its meaning is still stronger, because it should never be empty, no matter how poor the household is, people try to keep some djene (milk) in the jenerde. Thus, its meaning is symbolic showing the prosperity and dignity of the house. In addition there are calabashes which are eaten from, the luutirde for the milk and the kitorde for the rice pudding.

The leso is extremely well adapted to nomadic life, because it is made out of light wood and can be disassembled completely. Like the saga, it is usually given to a woman by her mother or her family. During the day, the straw mat of the leso is usually rolled up in order to protect the leso from the sun, and to prevent smaller animals from jumping on it.

During the rainy season, the dudal fire is constructed in front of the house. The dudal is an area of fire for the herd in order to relieve it from mosquitoes. During the night the herd stays around the dudal, not bothered by the smoke, and free of insects. The dudal also contributed to a general cleanness of the house, because the animals will not enter into the human sleeping space, and thus that area becomes free of their droppings. When nduungu (the rainy season) is over, the dudal fire is not made. The area of the dudal carries various taboos; a clay bowl can never been carried into the dudal because it can break; someone from another house does not have the right to "take" fire from the $d u d a l ;{ }^{6}$ a married woman who has her hair unbraided should not enter the dudal. The disrespect of these taboos causes misfortune, perhaps the illness or death of a calf or a cow, or it may cause an animal to be lost. Sometimes people sit down within the dudal (atino), but that is not common, and people do not sleep there. The dudal is simply seen as belonging to the herd.

It can be pointed out in this context that some of the origin myths of the WoDaaBe state that the cows of the WoDaaBe originated from water, and were lured to join people

5. This is only clothing belonging to the women. Men do not have handere. Men have takuubuut (sack for tea), tabauul (leather sack for clothing), and/or asjuukuwa'uu (this is a bigger kind of leather sack, also for clothing. But the last one generally belongs to a young man (kajedjo).

6. What can be done to prevent misfortune from this action is to leave one piece of charcoal (to take fire is to take charcoal) for the fire of the house to which the dudal belongs. People say that then the fire belongs to the house not the dudal. 
by the dudal. I cite a short version told to me by and elderly WoDaaBe person of high authority:

"Two children came out of water and they made a suurel (grass house), and sat down by that place. Later, cows came out of the water, and they stayed during the evening with the children. They wanted to come because the children had made fire for them. And the cows came, they stayed for the evening until they became used to the children. And then the children did a gurgiisi [a short migration movement]. The cow followed to every place the children went, because they had made them a fire" (Tape transcript 1997:3; see also M.Dupire 1962).

This origin myth thus sees the cows and people and fire all as elements of coexistence, the fire being the tie that unites animals and people.

The important decisions about migration are taken in the kinnal, which is a meeting of men of the lineage group. All men (kajedjo, dottijo, najedjo) can participate, even though they do not have their own house. Women do not have the right to enter the kinnal. A kinnal can simply be the meeting of two males discussing a movement, and it can be a large group of people. Usually it is the kinnal that decides the larger seasonal movements. The ardo is a powerful figure in deciding the migration patterns of the group, even though people do not strictly speaking have to follow his instruction, and everyone has the right of expressing their opinions. The garso (pl. warsobe) is an important person in collecting information affecting the migration patterns. A garso is a person who surveys areas, trying to find the best pasture for the migration group. There is some variation in how formal the position of the garso is within the group.

\subsection{Other economic activities}

WoDaaBe are specialized pastoralists and do not in general have other products to sell than their livestock and their by-products. Women are engaged in sippal (pl. sippe $)^{7}$ which is generally the trading of milk products. The income from sippal is not great, ${ }^{8}$ and can normally only be acquired if there is enough milk to trade. Animals have to be sold on a regular basis in order to buy millet, and today people usually have sheep and goats especially for this purpose, thus being able to refrain from the selling of cows. As with probably all pastoral groups, the WoDaaBe have been engaged in agricultural activities both in the recent past and a long time ago. Agriculture has usually been done as a way of reconstructing the herd. Most young and old WoDaaBe with whom I have talked, have at sometime during their lives been engaged in agricultural work. Sometimes cultivation has been integrated partly into the nomadic lifestyle; thus during the time that the field does not need work, the herder pays someone else to look after it and leaves with his cows. Niger is facing increased land pressure, and this strategy has become more difficult for herders. After the drought of 1968-1974, WoDaaBe were faced with extensive livestock losses, and thus many turned to agricultural labor or to migration work. Most of those who turned to migration work, sold medicine in neighboring countries. WoDaaBe are well known for their knowledge of medicines all over West Africa. Other migrational activities

7. A person doing sippal is referred to as sippowo (pl. sippobe).

8. Sippal is only conducted with non-WoDaaBe. If sippal takes place within the bush, then usually with Tuaregs, the payment is millet or sugar. There are two units of milk (this is pendidam, mixed with water), against one unit of millet. It is only in the markets in the town where one gets payment in cash. 
during this time included working as a security guard, and the styling of the hair of women from other ethnic groups. After the drought of 1984 however, increased competition for land in Niger made it more difficult to reconstruct the herd because this conflicted with agricultural activity. Increasingly many WoDaaBe thus turned to migrant labor, going to the various cities of Niger in addition to traveling to neighboring countries. During this time the range of activities related to migration work extended considerably. Now, WoDaaBe, for example, sell water, they sell tea in the bigger cities, they smuggle gasoline between the borders of Niger and Nigeria, they sell ropes and artisanal work, and they do dances and shows for payment (see K.Loftsdóttir 2002).

Many WoDaaBe, who work today as migrant laborers, have still not been able to reconstruct their herd since the 1984 drought. Most often all of their income goes into basic subsistence in the city. Some of those who have not been able to reconstruct their livestock stay in the bush, being provided for by their brothers, or working as a djokere, herding others peoples animals. However, by working as migrant laborers, they are not a burden on their extended families in the bush.

\section{WoDaaBe use of space and resources}

\subsection{The Sahel area}

The WoDaaBe occupy the Sahelian belt covering the greater part of Niger. The area, which is usually referred to by the term Sahel, is a "zone approximately $200-400 \mathrm{~km}$ wide, centered on the latitude $15^{\circ} \mathrm{N}$ in sub-Saharan Africa" (Advisory Committee on the Sahel 1984:3), characterized by fluctuating rain, low quality soil and dry heat. In the northern part of the Sahel in Niger, rainfall is between 100-350 mm, whereas in the southern part rainfall varies from 350 to $550 \mathrm{~mm}$, making rain-fed agriculture possible (P.Beaumont 1989:202). Annual rainfall in a particular area is very unpredictable. For example, in the department of Tahoua, annual rainfall varied (in the period from 1920 to1970), from $208.6 \mathrm{~mm}$ in 1942, to $581 \mathrm{~mm}$ in 1961, the average over the years being 403.6 (Ministry of Agriculture and Herding1972). E. Bernus has pointed out that annual rainfall does not tell the whole story, but the focus should be on what he calls "useful rain," which is the "part of the rainfall which plays an effective role in the growth of vegetation" $(1973 ; 129)$. The point is that two years with similar amounts of rain can give very different results, due to the distribution and the period of intervals between the rains. In order to be useful to the vegetation cover, rain must be distributed without too long breaks. Early rain, followed by lack of rain would cause seeds to germinate and die without maturing the vegetation cover (E.Bernus 1973). Useful rain can be seen as a rain above 3 $\mathrm{mm}$, which is "followed by a similar one within a week at the most" (E.Bernus 1973:129; see also P.Beaumont 1989:206). Thus both the timing of rainfall and the amount, are critical for vegetation growth.

Ecological studies of the Sahel have shown that even though the annual grasses have low biomass, they have relatively high protein content which makes them quality forage (R.Netting [1977] 1986:45). It has also been reported that livestock productivity in terms of weight gain, calving rate, and calf survival is better among migrating herders than sedentary farmers in the same areas (R.Netting [1977]1986.47).

The Thin-Tabaraden area is in the pastoral zone in the north of the department of Tahoua, but right to the northern limits of agriculture. Data has shown that the rainfall is 
highly unpredictable in this area. In the last century the area has gone through numerous periods of drought, leading to heavy livestock losses and famine.

\subsection{The year cycle for the WoDaaBe}

WoDaaBe count years in accordance with how many rainy seasons have passed, the concept hitande (pl. kiitale) referring to the passing from one rainy season to the next. ${ }^{9}$ The age of both people and livestock is counted in accordance with how many rainy seasons they have gone through. The tasks and problems of the seasons are obviously different and I will here try to describe some of their main characteristics. An overview of the seasons can be seen in Table $1 .^{10}$

TABLE 1. Overview of the seasons.

CeeDu - The dry season.

Kokkje- The first rain, grass starts to sprout, a time of great insecurity.

Korsol - Abundant rain, people see how the year will be, animals are more spread out.

Nduungu- There is water and tall grass, a time of pleasure.

Jawol - A transitional period between the rainy season and the cool season.

Dabbunde - General term for the cold season, characterized by the Harmatan wind.

Mobility is one of the most important strategies which WoDaaBe use to exploit their resource base, and thus I want to discuss it briefly before explaining the different seasons. Mobility is of several kinds, depending on seasons but also on the political and social environment. In my view, mobility is a key to understanding the WoDaaBe connection to land, but that is an issue to which I will turn to later in the paper. The WoDaaBe have linear seasonal movement (often called transhumance), traveling between the rainy season area and the dry season pasture. When the first rain starts to fall, people move to the north, to the area of the rainy season pasture. This movement is called Njakake. The movement back to the dry season pasture, is referred to as djolol. ${ }^{11}$ People often use the same wasarde, or water source for several months, and move regularly within the surroundings of that particular water source, a movement which is referred to as gonsul. Sometimes, however, people decide to move to a different water source (dimdol). Dimdol is a longer movement than gonsul and usually to a different water source, and thus often seen as a

9. Sometimes the concept hitande is used to describe a year that is very difficult. Mi nani hitande gore (this year was really difficult).

10. It should be pointed out that my discussion of the seasons follows the representation of the group among which I did my research, but it still corresponds well with Maliki's (1981) study. His year cycle however includes sudditte, between dabbunde and ceeDu, The year cycle I have represented, does not.

11. Another term with the same meaning as djolol, yet not as much used, is timoke. There is some difference between these terms. Mi timojii would refer more to seeing or going again to one's dry season pasture. 
movement to a different area of the seasonal pasture. In some cases, however, the concept dimdol is used to refer to a long movement in the surroundings of the same water source.

As previously stated, the WoDaaBe count years according to how many rainy seasons have passed. I will thus start my description of the year cycle in the beginning of the wet season, starting by describing kokkje which follows ceeDu (i.e. the hottest season). Kokkje is a season of great difficulties. The rain has started to fall, but it is scattered and both people and animal are weak after the ceeDu season. It is no longer possible to use hand dug wells because the rain has created small ponds in the spaces of the wells. The ponds are small and shallow which means that the water is silted and dirty. The primary goal of this season is to get nourishment for the animals, and thus WoDaaBe often say that they follow the rain.

The korsol season is defined as starting when grass has reached a certain height, making the cow able to get its necessary nourishment (the grass of kokkje is too short for the cows, only the sheep, goat and donkey can make effective use of it). However, the grass of korsol is tall enough for all livestock to make use of it. It is seen as having high nutrition value, because it is not too tall and it is fresh. This grass is considered the best found during the seasonal cycle. During this time people start moving (njakake) to the north to the wet season pasture.

During the nduungu ${ }^{12}$ it rains frequently. This season is defined by the grass having reached considerable height, and its stalks are starting to dry up, as well as to sprout. The jawol season is usually defined as the time when the wet grass (hudo) is finished or close to finished and only the dry grass (gene) remains. Both duungu and jawol are the times of prosperity and strong social interactions. Milk is abundant, and the price of millet is low. Camps are close to each other, which means that, in general, one is close to his or her family. The annual gathering of the lineages (worso) is held at the end of nduungu or in the beginning of jawol. During nduungu the organized government festival, Cure Sallée, takes place along with smaller dance gatherings. The important factor for festivals is that there remains water in the ponds, making it possible for many people to stay at the same place. During jawol the water in the ponds is almost finished and thus people usually do the worso at the end of nduungu (or the beginning of jawol), doing dimdol after the worso.

The dabbunde season can be described in its most broad sense as the cool season after the rain. Dabbunde is characterized by cool nights and stormy days. The sky often has a brown color, the sun is invisible, and the sand enters all places. Gonsul is not done as frequently as before, every 5 or 4 days, and it is a short movement only for approximately 20 minutes. It is a movement to different luggere (woody depressions). The lakes have dried up, and all water has to be carried from hand dug wells, both the water for animals and for people. The family does gonsul within the area in which the well is located. Because pasture is getting less and less, the cows are often given sa'anjo (a by-product of millet), especially those cows that are still milking or that are weak for some reason.

$\mathrm{CeeDu}$ is probably the most difficult season for the herders. It is a natural extension of the dabbunde except that it is no longer cold in the night, and the sun is intense. Water is more scarce, and the work related to it is extensive as I will discuss latter on. The pasture for the animals is close to exhausted, implying that additional fodder (sa'anjo) for the animals has to be bought at the market. The buying of fodder increases the stress of the

12. Nduungu is the time of extensive rain and grass. Some people defined it to me by stating that then Sabere, thorny seeds, come out. 
resources of the household, and the herder has to evaluate how many animals he is willing to sacrifice in order to buy fodder for the other animals. If a herder is too resistant to selling animals to buy sa'anjo, he could end up losing most of his animals if the year turns out to be a very difficult one. It is not uncommon during this time of the year that the animals are too weak in the morning to stand up by their own effort, and thus have to be pulled onto their feet by people. People tell me that ceedu used to be much shorter than today; now it starts early and last for many months (this may be because the WoDaaBe are much further north than several years ago). The houses are far from each other during this time, and social interaction is thus minimal. The dimdol movement is often done within $c e e D u$ and dabbunde. Dimdol is normally conducted because of lack of water and grass, and thus the family has to move to a new water source where wells and grass are more abundant. It is the father of the household who makes the decision whether or not movement will take place, and then when and for how long. Sometimes such decisions may be taken within the kinnal (the council deciding migrational movement), and thus several houses could decide to move together to a new water source. (see also A.Maliki 1981:1-13).

\subsection{The exploitation of water}

"Without water there is no house" (Interview Akali 1998).

As this quote indicates, water is not only the basic source of life but is also important in defining what is a home in WoDaaBe society. From the end of the rainy season and until it starts raining again, most work is in one way or another related to obtaining water. As the pasture close to groundwater sources is finished, it becomes increasingly time consuming to carry water to the house and to the animals.

Most WoDaaBe dig shallow wells that they call buli (sing. bundu) and from those wells, water is drawn for people and their animals. The wells are dug in clayey ground, found in the depression in the rather hilly savannah. These spaces where it is possible to create a well are referred to as wasarde. Most people have several buli, the numbers owned depend on the size of the herd, as well as on how much water the buli contains. When a bundu is made, one person enters the narrow hole, digging out the clay and strengthening the walls with grass. A second person stands on the surface, handing down the grass and receiving the clay (jase buli). The digging of the bundu is a time consuming activity that preferably must be attended to every day. If the bundu is not maintained on regular basis, people say that it will die, meaning that it will be without water.

The same wasarde space is used by different ethnic groups; WoDaaBe, Fulani, Arabs and Tuaregs. The ownership of waterholes is private in the sense that the maker of the hole has a prior right to use it. This is generally accepted by all ethnic groups in the area. People tell me that if someone would break this norm, and go for someone's waterhole before the owner was finished using it, other people would make comments and express dissatisfaction. If the owner, however, is finished using the waterhole it can be inappropriate for him to refuse another person use of it. Sometimes people share their buli systematically with others (luu'hural buli). For example, if in a given place one person has three buli, and another person three, they might arrange their schedules so as not to come the same day, in order for each person to be able to water from six buli each time.

Women are responsible for carrying water to the house. If there is a grown daughter in the household, she often gets the task of carrying water to the house. Older women sometimes "borrow" one of their granddaughters to perform this task. Early in the 
morning she leaves for the wasarde, and frequently she returns at the time when the sun goes down. She draws water from the buli in a leather sack called wakasjival, and pours the water into another sack made of goatskin (satju) which she then ties to the belly of her donkey. The satju is tied to a tree inside the house and rubbed with water, which makes the water cold, even at times when the temperature is really high. The distance between the house and the wasarde means that the women cannot go on more than one trip each day. Whether or not the women has to go everyday or every other day, (I have never heard about anyone who goes every third day), depends on the number of satju and donkeys (to carry the satju) belonging to the house, as well as the numbers of people and animals drinking the water. This water is used for all household activities: it is used for drinking, bathing, washing cooking utensils, and for cooking as well as to water those animals who are too young, old or weak to go to the buli. Sometimes when the satju reaches the house, the children cry in excitement, and the calf, sheep, and goats fight to be the first one to get to drink. If a man has more than one wife, each one has separate suudu. The wives will take turns cooking for the husband, each wife does of course cook for herself and her children, and needs thus to have water for her house.

Just as it is the woman's responsibility to carry water for the house it is the man's to water the animals. During the dabbunde and ceeDu season, the animals are watered every other day, for the simple reason that the wells are far away. In some cases, the cows drink every third day, but that is only if the buli are very far and it is not very hot. In the morning, the animals are separated into those that are seen as capable of going to buli, and those who have to stay at home. The newborns are left behind, as well as those who are old, or just for some reason too weak to tolerate the long walk to the buli. All the animals are watered at the same place (the watering of animals is called "jarne na' $i$ "). The water is carried from the buli to the animals. It is drawn from the buli in a vakasiival, but put into an iron container called akalii. This is the same container that the animals are given salt from, and in which the cows are sometimes given sa'anjo (the by-product of millet). People told me that the animals are watered at some distance from the buli because the animals could fall into it, and if droppings go into the water the animals do not want to drink it. This precaution has very clear health consequences for people as well. The order in which the animals are given water depends on the strength of the species. First the sheep are given water, then the goats, the calves, and finally the adult cows. The goats are stronger than the sheep and are better able to tolerate thirst.

During the ceedu (the hot season) the majority of the time goes not into working at the buli directly but rather into travel back and forth between the wasarde and the house. For many people it is from 3 to 5 hours walk just one way, thus they have to spend from 6 to 10 hours per day simply walking to and from the water source. In the beginning of the dabbunde (the cool season), the time to the buli could be 1 to 2 hours. After the rain has finished, the pasture closest to the wasarde gradually becomes used up.

\section{The Politics of land in Niger}

\subsection{The legal framework of claims to land}

Prior to the colonial period the local Tuareg chiefs controlled the arrival of new groups into the pastoral area. When Niger was colonized, the Tuareg no longer had control over who were permitted into the area. Population pressure in the south led to the spread of farmers into grazing areas. The Tuareg society had been heavily stratified, and relied on 
the labor of slaves. As slavery diminished, smaller animals, which are in general more labor intensive were replaced by cattle, which are less labor intensive. (P.Beaumont 1989:204). The freed slaves also moved toward the north, seeking economic opportunities in cattle holding, which also served to enhance their social status (S.Baier 1980:136). Population pressure in the south led to cultivators moving increasingly to the north, thus depriving pastoral groups of their dry season pasture, pushing them also farther north.

In 1954, the colonial administration legislated the northern limits of cultivation, which in effect marked the areas reserved for herders. These laws were revised by the government in 1961. Under these laws, crop producers would not be able to collect damages done to their crop by livestock in areas north of the limits (E.Eddy 1979:137; A.Habou et al. 1990: J.Sutter 1982). The laws defining northern limits to agriculture have not been enforced, and agriculture has slowly been moving to the north. Decreased yields from agriculture and population pressure have led cultivators to pockets of land suited for agriculture within the pastoral zone, thus depriving the pastoral economy of important pasture and water sources, considerably limiting their area of exploitation (J.Thomson 1981:123-124). When conflicts arise between herders and agriculturalists, there has been a tendency among administrators to take sides with the cultivators, enabling them to collect compensation for lost crops even within the area designated for pastoralism (E.Eddy 1979: 137; A.Habou et al. 1990: J.Thomson 1981). The land tenure law also encourages grain production. Through land cultivation the cultivators gain some rights to that land, whereas there has been no official recognition of land use rights due the livestock producer (E.Eddy 1979:137). In 1961, the pastoral zone was defined as the zone for modernization of the pastoral economy, thus opening the way for initiating projects in the area (A.Habou et al. 1990:27).

Niger's increased population growth has made it extremely important that laws regarding land rights are clear and coherent. This has not been the case, whereas law regarding land tenure has changed with changes of presidents in Niger. In addition, there still exist customary rights, and rights based on Islamic laws. This has caused general confusion over land rights and allocations of land. The Rural Code, which has been in preparation since 1986, includes the objective to "establish a legal framework for the appropriation, tenure and management of the natural resources vital to agriculture and livestock production" (C.Lund 1993:2). Thus, the goal of the Rural Code would be to establish coherent land policy for all land use in Niger.

Probably, one of the most important rights attributed to herders in the Rural Code, is the acknowledgement of the existence of an area of attachment for a nomadic group ("terroir d'attache,"). This can be defined as "a geographic area which regularly, for the majority of the year, is essential for a group of people, and to which they are attached, and to which they move back and forth due to transhumance, migration, or exodus done by part or the whole group" (A.Habou et al. 1990:35). This appropriation is not done on an individual basis but on a collective basis. Even though one area of attachment can be attributed to individuals from the same ethnic group or from different ethnic groups, it is still seen as the ideal to attribute one area of attachment to one ethnic group (A.Habou et al. 1990:51-52). The establishment of such resources is considered important to the state as part of a process of legalizing the resource claims of a group. Other things legitimizing claims to land, are investments in the area, such as wells, and how long a particular group has stayed in the area (A.Habou et al. 1990:35). According to interviews with personnel at the Ministry of Agriculture and Herding in Niamey, a well is especially important in this context, because a group that has a well has the control over an area five meters around the 
well, and can thus also prohibit other groups from building a well in the same area. This has developed to the point today that in order for groups to claim land, they begin by claiming water points.

\subsection{WoDaaBe and Land Entitlement}

Many WoDaaBe both young and old, in the bush and working as migrant laborers, have expressed to me a deep concern over their future and their future right to land. Many middle-aged WoDaaBe in Niamey, actively seek to find financial support for the building of cement wells, which they hope will strengthen their rights to land. Individuals often claimed in informal discussions that they were originally marginalized in the process of land entitlement, because most projects conducted in the past in the pastoral zone have been done for the Tuaregs. Many of these projects built wells and were thus, probably unknowingly, strengthening the resource claims of the Tuaregs versus the WoDaaBe. At the Minister of Agriculture of Herding, I was told that there exists no document showing the distribution of ownership of wells in Tahoua, nor any document showing sources of financing of these wells. The Pastoral Atlas of Central Niger which shows the distribution of shallow wells in the northern part of Tahoua, supports the WoDaaBe claim that most of the wells are owned by Tuaregs ${ }^{13}$ (J.Swift and W.Campbell 1984:10,12). Thus if this is correct, the higher proportion of well ownership among Tuaregs is not due to greater cultural attachment to their resources, but rather reflects that they have been provided with the means of claiming attachment to resources.

Interviews and informal discussions with government officials and developers, as well as written documents show that the WoDaaBe are conceptualized as having no attachment to a place of their own. They are frequently pictured as migrating over long distances without specific attachment to places. I have also heard it implied that they do not really have strong rights to land because they were the last to arrive in Niger. It seems often to be assumed that they are not interested in the issue of land and if they are, they should have done something about it before, and that anyway they are the last in the line. It is in this context that I find it important to discuss WoDaaBe conceptualization of land, use of space, and notions of origin. There seems to be general misunderstanding and simplification of this issue, as well as over generalization based only on a few WoDaaBe groups.

\subsection{WoDaaBe conceptualization of land}

Do you know siibiiru WoDaaBe? There is a sibiiru which is a symbolic one, it is not a true sibiiru. But that time you are born, there is this something which gives you power inside the stomach of your mother. This is your nourishment. This something gives you all you need. This is the sibiiru. That time you are born, people take redja [razor blade] and cut this because it is long....., when they have cut it, they put the sibiiru inside the earth. They make a small hole, like half

13. According to the Atlas (J.Swift and W.Campbell 1984:10,12), the Tuareg own 61 shallow wells and the WoDaaBe own 4 within the department of Tahoua, to the north of the limits of agriculture. What is defined as a shallow well (puisard in French) is not defined in the text. It should also be kept in mind that the Tuareg are more numerous than the WoDaaBe in the area. 
meters deep, and cover it with earth. This is called "up'ki," "sibiiru ma oubama" [You bury your sibiiruu]. Sometimes, if you are talking to someone and you are asked "from where do you come? Where is your region? Where are you born?" You want to tell him where your sibiiru is (Tape transcript 1998).

The concept of sibiiru in this context refers to a place of origin, ones roots, but not to one's individual origin. It refers to the place where ones forefathers were born, the origin of the social group, of the extended family. It is a symbolic association of the womb and the land where one originated, united in the nurturing cord.

The WoDaaBe vocabulary also identifies what can be formulated as an area of attachment, usually referred to as gari am, lehidi am, or ngendi am. These terms do not necessarily refer to one's place of origin, but to the place where one is brought up, or where one lives. ${ }^{14}$ To explain the difference between the use of these terms, (gari, lehidi, ngendi, sibiiru), I will give an example. A man is born in Chadawonka, as his ancestors were there for several generations, but his lineage group moved further north to Tchin Tabaraden when he was a small child because of increased expansion of agriculturalists. He would, if asked where his gari is (to wi'eta gari ma?), identify it as Tchin Tabaraden; however, he would identify Chadawonka as his sibiiru.

Even though the term gari is often used in a general way for one's home area, the term has also a more specific meaning. The more literate meaning of gari, or an area of attachment, is the dry season pasture, or the areas around the wasarde most frequently used by the group. Even though the rainy season pasture is often in the same area year after year, it is not really conceptualize as being the gari. An attachment to one place is also documented by other researchers (see A.Maliki 1981:72-73; A.Habou et al. 1990:13) and thus it can be assumed that such an attachment to land is a part of WoDaaBe tradition and identity.

As probably with all groups calling a place a home, the WoDaaBe have a deep knowledge of their gari, knowing the landscape intimately. This is mixed with the existence of memories, giving the attachment to land both a personal and a historical dimension. People remember both places where members of their families are buried (walorde), as well as places that signify events in their own lives. Places and history intermix, because history takes place in places. One spot is the site where a man in the family was killed by Tuaregs, another spot is the site where the group did their annual worso gathering a long time ago.

I hope to have shown in this discussion that the WoDaaBe have thus both a conceptualization of a place of origin (sibiiru), and a place of attachment (ngendi, gari, lehidi), and that these places are the locus of history and thus identity (see also K. Loftsdóttir 2001).

\subsection{Understanding WoDaaBe movement within a space}

So why is the belief so dominant that the WoDaaBe have no particular connection to a place? I think the reason can be sought, at least partly, in a lack of understanding of the different kinds of migration of the WoDaaBe. Their exploitation of resources over a vast

14. There is some difference between the terms gari and ngendi on the one hand and lehidi on the other. Lehidi can also have a much broader meaning, referring to a much larger area, such as a department or a country. Its meaning thus depends somewhat on the context in which it is placed. 
area can probably create the illusion that they have no attachment to the land they use, or that their use of it is not structured. I want to discuss the different kinds of migration in the light of the concept of areas of attachment that I have pointed out exist in the WoDaaBe vocabulary.

The different movements can be classified according to two main criteria; some are differentiated on the bases of the length of movement, and others refer to the season of movement. But in addition, possibly contributing to the misunderstanding that WoDaaBe do not have attachment to land, there is the historical migration called perol. Perol, however, is migration out of the ordinary, often temporary exploitation of new and foreign spaces. Thus looking at the main migration patterns we have the following kinds:

\section{TABLE 2. WoDaaBe Migration Patterns}

1. Movement which is defined according to length but not tied to seasons:

Gonsul -short movement, usually not more than 20 minutes, within the same wasarde space (i.e. same water source).

Dimdol-movement that takes a longer time than gonsul and is usually to a different wasarde, i.e. a different water source area.

Girgusaki - is a shorter movement than gonsul, people usually move no further than to where they can still see their last place (winde). It is not commonly done.

2. Movement based on seasons:

Djolol-movement after the rain is finished, people move south to go to the area where they spend the dry season. (sometimes people say mi timi, mi timoy, for this type of gonsul.

Njakake - movement north at the time of the rain.

3 . Movement out of the ordinary, to another remote area:

Perol - movement that implies going a long distance, leaving one's area for a specific period of time. This is only done in exceptional cases.

There are other types of movements as well, but they are of less importance to the purpose of this paper, and I will only briefly mention them. These are identified by the group that I worked with as: Sottol, ${ }^{15}$ a movement to the east (gada) after someone has died at the camp; Kabonojki, the splitting up of the house and the herd, i.e the cows migrate but the house stays in place for a brief period; and Biggal, which is similar as Kabonojki but done for a longer period (more than 3-4 days). Kabonojki would for example be conducted when there is a taboo (mboda) on a day to do gonsul, but for some reason it would be important to move the herd. Biggal, however, is done if it is for some reason seen as desirable to split up the herd and house, thus increasing the mobility of the herd. Biggal could, for example, be seen as desirable if the cows are grazing on a harvested field (gesa) close to human settlement, or during the kokkje season, where herd mobility is extremely important.

It is interesting to observe that different groups of WoDaaBe do not seem to use the same terminology for different movements. Bonfiglioli, who has mostly done research in

15. It can also be pointed out that in daily talk, the phrase sottol means to move a little. $M i$ sottira do (I move a little to the side), might be used if people were sitting together and someone wanted to sit down in a different place. Among the group studied, however, the term sottol, only refers to a migrational movement if someone has died in the camp. 
Northwest Niger, identifies the seasonal linear movements as duumol (to the wet season pasture) and kottol (to the dry season camp) (A.M.Bonfiglioli 1998:9). In Nicholas Schareika's study on the WoDaaBe in Southeastern Niger, he distinguishes between four main types of moments: the perol, a historical migration; Bartol, a seasonal migration; Goonsol, a middle range movement within one ecological setting; and sottol which is a short range movement (N.Schareika 1998:4). However, even though the terminology used by different lineage groups is different, the main movement distinctions are still the same, preserving an important distinction between movement where resources are exploited within one's "country," and outside it.

The lineage group with whom I have mostly stayed, spends the rainy season to the northwest of Tchin Tabaraden, but moves in the dry season to the southwest of Tchin Tabaraden. Between October 1996 and April 1997, they used only two wasarde, in Gann and Abalak (thus probably only one dimdol). In years that are difficult due to lack of water or pasture, the group sometimes moves northwest earlier and makes use of other wasarde (dimdol), which can still be said to be within the same area. However, during the drought in 1985, some of the group moved all the way down to Nigeria (perol), in the hope of saving some of the livestock. The families moved back to their area after the drought. Thus, in most cases, in relatively normal conditions and normal years, this group uses the same resources and the same space.

The perol, the movement far away from one's gari, is thus an exception and a response to specific circumstances. People leave their area of attachment because they feel they do not have another choice. In most cases, people want to return back to their gari, and do so if they see it as possible and desirable. The following account shows the conditions under which perol is usually done.

WoDaaBe do lot of perol but they always try to return to their gari. During kuunsiter [the drought of 1984], a great deal of animals died. Some people went to Gaja, which is not far from Benin, some went to Dosso. Some went to Nigeria; to Gusau, Funtua, or Sinkafi. But all these families came back for their gari. The government did have a center for Tabalak Majrwa, where those who did not have any cows left, stayed when they came back. My father had gone to Sinkafi and he came back to Niger. But my grandparent died not far from Sinkafi. My grandfather died at Gidan Sale, my grandmother died at Ibiiri. Shortly before it had rained and people saw they could finally go back, but before they left, my grandparent died. (Tape transcript 1998).

Perol is thus an adaptive strategy used both in difficult ecological and political situations. The movement can be permanent, even though probably in most cases people wish to return to their gari if they feel they have the choice.

\subsection{The history of the WoDaaBe and the politics of land}

My people stayed in Adar before Niger was made. Father-father-father [of] my father stayed in Adar. All these people have their history in Adar. All these people died at Chadawonka in Adar. They did not die in a different country and were then carried to Chadawonka! They all died at Chadawonka, because that is where their history is (Tape transcript 1998).

Chadawonka is part of the Adar area, which is in the northern part of the department of Tahoua. The lineage group stayed in the area of Chadawonka, including the areas of Zangebe and Labanda. Chadawonka was authorized as a market place by the colonial 
authorities in 1940 (Brouin 1944:9). An old man (Tape transcript 1997:5) says that his lineage segment is "born" in Chadawonka, meaning that all members of his lineage both in the past and present were born at this place, as well as that the segment itself was established in Chadawonka. The first formulation of the linage segment hence took place in pre-colonial times, even though it was not officially established until ca. 1955, when they gained their own hakkimidjo. Another men of high authority within the WoDaaBe society remembers the time before any town was established at Chadawonka. WoDaaBe then shared this area with Tuareg groups (which they call Iborogan), creating shallow wells to water their animals within the two wasarde of the area (Tape transcript 1998). The time before and during the beginning of the colonial period was a time of great insecurity; the WoDaaBe populations were suffering from raids from Tuareg groups, taking both people and animals. During the colonial period, the WoDaaBe like other Fulani in the area, were heavily taxed by the colonial authorities, at one point paying probably the highest tax of all groups in Tahoua (Durand Viel 1947:3; see also discussion in M.Dupire 1965).

Around 1959, the lineage segment started to move north to Tchin Tabaraden, thus from the place their forefathers had stayed for at least four to five generations. The area of Chadawonka had become more densely populated, the agriculturalists were pushing further and further north, and thus the bush had "died" (ladde watii). Wild animals had disappeared, fields had been extensively established, pasture was insufficient, and trees had died, meaning that pastoral people were no longer able to sustain their herds in this area. The lineage moved in small groups over a period of few years to the area of Tchin Tabaraden, which was then sparsely populated with a recently established market. Even though most of the young people today have not been brought up in the Chadawonka area, it still remains an important symbolic place of origin.

Many WoDaaBe find it strange that other ethnic groups will claim that they are newcomers to Niger. They state that this is wrong, based on their own historical knowledge. They emphasize that even though probably some or many WoDaaBe lineages are newcomers to Niger, there still have been WoDaaBe in Niger for many generations. They also find the claim illogical, because Niger itself is an artificial creation from the late 20th century. One man pointed out that even though the WoDaaBe had been more to the south several hundreds years ago, they did not stay in a different country, because all the countries were different at that time. WoDaaBe had perhaps been in the south of Adar several centuries ago. If they were in Katsina, then that is only walking distance from Adar. "Niger or no-Niger" one man told me, "WoDaaBe were in Adar" (Tape transcript 1998).

Akali also points out that when Niger was made, WoDaaBe were on the right side of the borders; thus, he asks, how can they be anything else than Nigeriens? Niger is a new creation, dating back only several decades, while his people have stayed in the area for several generations, being in Niger at the time of creation of the Niger state. An elderly Fulani furthermore told me, "This people [i.e. the lineage Godjanko'en] do not know any other country than Niger. If they do not belong in Niger, no one else in Adar does. These people are the children of Adar" (Tape transcript 1998:2).

\section{Conclusion}

In my discussion I have attempted to contribute to an understanding of WoDaaBe land use, and their conceptualization of land and history. Land issues have become central issues in Niger, and many WoDaaBe feel that they have been marginalized in this process, 
because of their general lack of education, lack of involvement with the state, and misrepresentation. The latter has to do, in many WoDaaBe views, with ethnic groups (i.e. those in power) who lack understanding of WoDaaBe historical development and WoDaaBe land use, something I observed to be correct in many cases. As my discussion has shown, WoDaaBe occupy large areas of land, in order to use it optimally in the context of its ecological possibilities. Seasonal movement, as a form of risk management is a crucial factor in use of land, and takes place within what they see as their area. Movement outside this area is a necessary response to extreme situations, and in most cases is not a desired choice. The group that has been the focus for this paper, has occupied the same area for many generations, but were forced to move north of it, because of agricultural expansion in their area of attachment. This area, which they conceptualize as their navel or birthplace, embodies their history from pre-colonial times until the present.

It is, however, important to emphasis that my example of history and land use among WoDaaBe is only one lineage group of many. There is a great diversity existing within WoDaaBe society, and the historical development of all lineage groups is not the same.

As various theorists have pointed out, history has to be seen in the context of politics and power. History is not simply the documentation of the past but has to do with the relationship between the past and the future. Also the way in which the past is understood often has to do with current political and cultural contexts. Some versions of history are institutionalized whereas others are subordinated (See for example; Popular memory group 1982). Therefore, in a large political project, defined as that "of debating and struggling over the whole social future," memory and history are vital resources (Popular memory group 1982:244). The inter connectedness of ecology, politics, and history, of domination and history, and of the state and history are complicated issues that have not been discussed here on a theoretical level. It is clear that the WoDaaBe, though politically subordinated in Nigerian political discourse, have been very much absent from historical works and works that analyze state processes. Though much research remains to be done on WoDaaBe origins and environmentally adaptive migration history and land tenure, their voice needs to be heard as a legitimate one in the national discourse.

\section{List of References}

Advisory Committee on the Sahel.

1984. Environmental Changes in the West African Sahel. Washington, D.C.: National Academy Press.

Baier, S.

1980. An Economic History of Central Niger. Oxford: Clarendon Press

Beaumont, Peter.

1989. Drylands: Environmental Management and Development. London and New York: Routledge.

Bernus, E.

1973. Drought in Niger Republic. Savanna. 2(2);129-132. 
Bonfiglioli, Angelo-Maliki.

1998. In Search of Light: From Traditional Knowledge to Rural Development. Unpublished paper given at the seminar; Crisis and Culture in Africa - with Special Emphasis on Pastoral Nomads and Farmers in the West African Sahel. Uppsala, Sweden 27-30 March 1998. The Nordic Africa Institute.

Brouin, $\mathrm{M}$.

1944. Élements de Monographie de Tahoua. Unpublished document in Archives Nationales du Niger.

Dupire, $\mathrm{M}$.

1962. Peuls nomads: Étude descriptive des WoDaaBe du Sahel Nigérien. Institut d'Ethnologie.

Dupire, $\mathrm{M}$.

1965. The Fulani. Peripheral markets of a Pastoral People. In Markets in Africa. P.

Bohannan and G. Dalton editors. Pp. 335-362. New York: Doubleday and Co.

Durand Viel.

1947. Rapport d'une Tournée de Recensement Effectué par l'Administrateur des Colonies Durand Viel. Colonie du Niger. Cercle de Tahoua. Le 14 Janvier 1947. Document obtained at the National Archives of Niamey.

Eddy, Edward D.

1979. Labor and Land Use on Mixed Farms in the Pastoral Zone of Niger. Monograph

III. Livestock Production and Marketing in the Entente States of West Africa.

University of Michigan: Center for Research on Economic Development.

Evans- Pritchard, E. E.

1940. The Nuer: A Description of the Modes of Livelyhood and Political Institutions of a Nilotic People. New York and Oxford: Oxford University Press.

Fratkin, Elliot

1997. Pastoralism: Governance and Development Issues. Annual Review of Anthropology 26:235-261.

Galaty, John G. and Douglas L. Johnson.

1990. Introduction: Pastoral Systems in Global Perspective. In The World of Pastoralism: Herding Systems in Comparative Perspective. John G. Galaty and Douglas L. Johnson, editors. Pp. 1-31. New York: Guilford Press.

Greenberg, James B. and Thomas K. Park.

1994. Political Ecology. Journal of Political Ecology, 1:1-12.

Habou, Akilou, Issoufou Any and Moussa Yacouba (supervision: Michel Keita)

1990. Code Rural et Pastoralisme: Deuxième partie. Situation Actuelle Propositions.

Republique du Niger. Secretariat Permanent du Comité National du Code Rural.

Johnson, Douglas L.

1969. The Nature of Nomadism: A Comparative Study of Pastoral Migrations in Southwestern Asia and Northern Africa. Chicago: The University of Chicago, Department of Geography Research Paper No. 118.

Khazanov, A. M.

1994. Nomads and the Outside World. Cambridge: Cambridge University Press.

Little, Paul. E.

1999. Environments and Environmentalism in Anthropological Research: Facing a

New Millennium. Annual Review of Anthropology, 28:253-284. 
Loftsdóttir, Kristín.

2002. 'Knowing what to do in the City? WoDaaBe pastoral nomads and Migrant Workers in Niger. Anthropology Today, 18(1):9-13.

2001. Birds of the Bush: WoDaaBe Distinctions of Society and Nature. Nordic Journal of African Studies, 10(3):280-298.

2000. The Bush is Sweet: Identity and Desire among the WoDaaBe in Niger. Unpublished Ph.D. dissertation. Arizona: The University of Arizona.

Lund, Christian.

1993. Waiting for the Rural Code: Perspectives on a Land Tenure Reform in Niger. International Institute for Environment and Development, Paper no. 44.

Maliki, Angelo B.

1988. Dudal. Histoire de famille et histoire de troupeau chez un groupe de Wodaabe du Niger. Cambridge: Cambridge University Press.

1981. Ngaynaaka: Herding According to the WoDaaBe. Rapport Préliminaire Discussion Paper. Republic of Niger. Ministry of Rural Development. Niger Range and Livestock Project. Unpublished Material.

Ministry of Agriculture and Herding.

1972. Modernisation de la Zone Pasturale du Niger. Institut d'Elevage et de Medicine Veterinaire des Pays Troupicaux (France). Laboratoire National de l'elevage et de Recherches Veterinaires Niamey. Etude Agrostoligique no. 33.

Mohammadou, Elridge.

1970. Lexique Fulfulde comparé. Parler des Jallinko'en de l'Ader Yaunde. Centre Fédéral Linguistique et Culturel (obtained at the Institut de Recherches en Sciences Humaines).

Netting, Robert M.

1986 [1977]. Cultural Ecology. Illinois: Waveland Press, Inc.

Nicolaisen, Johannes.

1963. Ecology and Culture of the Pastoral Tuaregs: With Particular Reference to the Tuaregs of Ahaggar and Air. The National Museum of Copenhagen. Danmark: Andelsbogtykkeriet i Odense.

Ngaido, Tidiane.

1993. Land Tenure and Social Structure of the Halaybé. In Risk and Tenure in Arid Lands: The Political Ecology of Development in the Senegal River Basin. Thomas K. Park editor. Pp. 145-182. Tucson \& London: University of Arizona Press.

Park, Thomas K.

1993. Ecology and Risk Management: The Case for Common Property. In Risk and Tenure in Arid Lands: The Political Ecology of Development in the Senegal River Basin, Thomas K. Park editor. Pp. 293-330. Tucson and London: The University of Arizona Press.

Popular Memory Group.

1982. Popular Memory: Theory, Politics, Method. In Making Histories: Studies in History Writing and Politics. Richard Johnson, Gregor McLennan, Bill Schwarz, and David Sutton editors. Pp. 205-252. Minneapolis: University of Minnesota Press.

Rain, David.

1999. Eaters of the Dry Season : Circular Labor Migration in the West African Sahel. Boulder and London : Westview Press. 
-uSchareika, Nikolaus.

1998. Environmental Knowledge and Pastoral Migration among the WoDaaBe of Southeastern Niger. Unpublished paper given at the seminar Crisis and Culture in Africa - with Special Emphasis on Pastoral Nomads and Farmers in the West African Sahel. Uppsala, Sweden 27-30 March 1998. The Nordic Africa Institute.

Sutter, John W.

1982.Commercial Strategies, Drought, and Monetary Pressure: WoDaaBe Nomads of Tanout Arrondissement, Niger.Nomadic Peoples.11(October):26-60.

Swift, Jeremy.

1979. West African Pastoral Production Systems. Institute of Development Studies. University of Sussex. Working paper \#3. University of Michigan.Center for Research and Development.

Swift, Jeremy and William Campbell.

1984. Pastoral Atlas of Central Niger. United States Agency for International Development. Niger Range and Livestock Project. Maps by Ken Wass and Alick Newman. Niamey: Université de Niamey, Institut de Recherches en Sciences Humaines .

Thomson, James T.

1981. Les Associations d'Eleveurs Nigeriennes: Analyse et Cadre Instutionnel. Rapport Préliminaire - Discussion Paper numéro 6. Project Gestion des Paturages et Elevage Tahoua, Niger. United States Agency for International Development. Republique du Niger. Ministere du Development Rural. Service de l'Elevage.

\begin{abstract}
A general conception among many government officials and those working in relation to development seems to be that WoDaaBe simply do not have attachment to land, and traditionally have had no conception of land as a home. These issues are increasingly important in present day Niger, where claims of land have become a very central issue. The goal of this paper is to discuss resource use by a specific lineage group of WoDaaBe and their conceptualization of land. I will explain the dynamics of the seasonal movements of WoDaaBe, which I believe are partly the reason that WoDaaBe are often seen as not having an attachment to land. I will also discuss concepts tied to the WoDaaBe conceptualization of land. I place my discussion in a broad political and ecological context, explaining the WoDaaBe situation within the nation state.
\end{abstract}

Keywords: Niger, WoDaaBe, land tenure, land policy, pastoralism, Sahel, nation state.

\title{
Resumé
}

Il est généralement pensé par les administrateurs et ceux qui s'occupent du développement au Niger que les WoDaaBe n'ont pas d'attachement à la terre et ne possèdent même pas l'idée d'un terrain comme lieu de résidence. De plus en plus, ces questions deviennent important au Niger où les demandes foncières sont devenues un sujet fondamental. Le but de ce travail est d'utiliser un lignage des WoDaaBe et leur conceptualisation foncière afin 
de critiquer ces idées. J'expliquerai les dynamiques migratoires des WoDaaBe qui sont à la base des croyances administratives au Niger que les WoDaaBe n'ont pas d'attachement à la terre. Je discuterai aussi les idées WoDaaBe liées à leur conceptualisation territoriale. La discussion aura un côté politique et écologique générale mais se situera aussi dans le contexte de la politique nationale du Niger.

Mots clefs: Niger, WoDaaBe, régime foncier, politique foncière, pastoralisme, état moderne.

\section{Resumen}

Un concepto general entre muchos oficiales y éstos del gobierno que trabajan en asuntos de desarrollo es que WoDaaBe simplemente no tiene afición a las tierras, y que tradicionalmente no ha tenido ningún concepto de la tierra como hogar. Estas contenciones son cada vez más importantes en el día actual en Niger, donde las demandas para tierras se han convertido en una lucha muy central. La meta de este papel es discutir el uso del recurso por un grupo específico del linaje de WoDaaBe y de su conceptualización de la tierra. Explicaré la dinámica de los movimientos estacionales de WoDaaBe, que creo en parte estos son la razón que WoDaaBe está visto a menudo como un grupo que no tiene afición a las tierras. También discutiré las ideas atados a la conceptualización de WoDaaBe de la tierra. Coloco mi discusión en un amplio contexto político y ecológico, explicando la situación del WoDaaBe dentro el estado y la nación.

Palabras claves: Niger, WoDaaBe, arrendamiento de la tierra, política de la tierra, pastoralism, Sahel, estado, nación. 